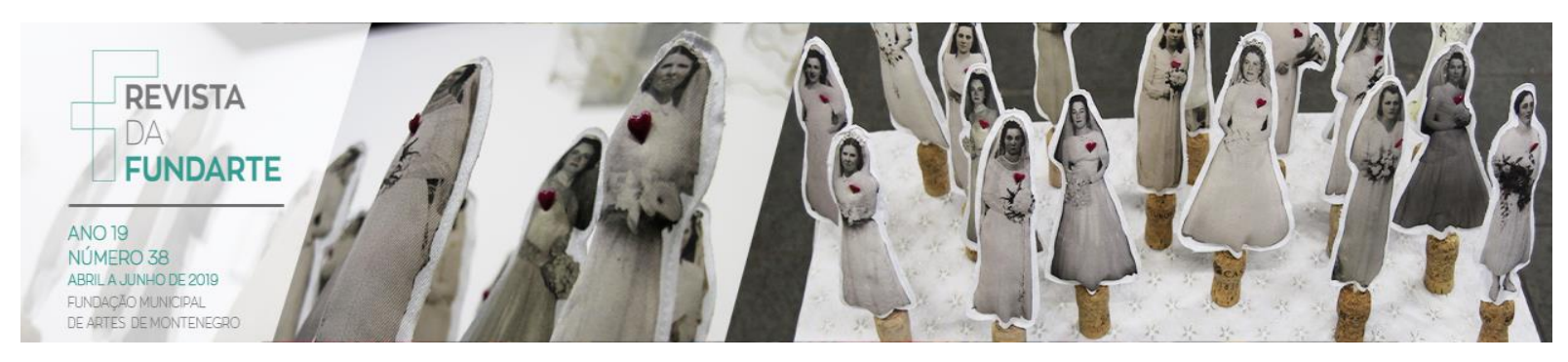

\title{
PROCESSOS FORMATIVOS EM TEATRO: ESTRATÉGIAS DE CRIAÇÃO MOBILIZANDO O TRÂNSITO DA ATENÇÃO NO PROCESSO CRIATIVO
}

Vanessa Corso Bressan ${ }^{1}$
Marcia Berselli2

Resumo: $O$ artigo apresenta a perspectiva de um processo criativo compreendido enquanto formativo, a partir da análise de práticas desenvolvidas por um grupo misto, formado por pessoas com e sem deficiência. $O$ enfoque na diversidade e nas relações estabelecidas entre as funções da cena permitem problematizar a exigência de especializações e competências prévias no processo de criação. Destaca-se o trânsito da atenção enquanto um dos mobilizadores do processo, estimulado a partir de estratégias de criação que enfatizam a acessibilidade. Espera-se contribuir com o campo das Artes Cênicas, destacando modos operativos para processos criativos e formativos que evidenciam as diferenças individuais - de corpos, habilidades e repertórios - enquanto potência criativa.

Palavras-chave: Estratégias de criação; Práticas cênicas acessíveis; Atenção.

\section{FORMATIVE PROCESSES IN THEATRE: CREATING STRATEGIES MOBILISING THE ATTENTION TRANSIT IN THE CREATIVE PROCESS}

\begin{abstract}
The article presents the perspective of a creative process understood while formative, from analysis of practices develop by a mixed group, formed by people with and without disabilities. The focus on diversity and on the relations between the scene functions allows to problematize the requirement of prior specializations and competencies in the process of creation. Stands out the attention transit while one of process mobilisers, stimulated from creation strategies that emphasize accessibility. It is expected contribute with the field of Performing Arts, highlighting operating modes to creative and formative process that evince the individual differences - of bodies, skills and backgrounds - whilst creative potencies.
\end{abstract}

Keywords: Creation strategy; Accessible scenic practices; Attention.

\footnotetext{
1 Tem experiência na área de Artes. Acadêmica do Curso Bacharelado em Artes Cênicas Habilitação Interpretação Teatral, na Universidade Federal de Santa Maria, com ingresso em 2015. Atualmente realiza um período de mobilidade acadêmica na Universidade do Minho - PT. Participante da pesquisa, \&quot;Procedimentos e práticas de colaboração artística horizontal: as quatro funções da cena como mote para o jogo\&quot;, coordenada pela Profa. Ma. Marcia Berselli. Tem interesses em: teatro, atuação, encenação, processos criativos, circo, clown, práticas contemplativas.

2 Possui graduação em Teatro pela Universidade Federal do Rio Grande do Sul (2012) e mestrado em Artes Cênicas pela Universidade Federal do Rio Grande do Sul (2014). Atualmente é professor assistente da Universidade Federal de Santa Maria. Doutoranda no Programa de Pós-Graduação em Artes Cênicas (PPGAC/UFRGS) com a pesquisa \&quot; Abordagens à cena inclusiva: princípios norteadores para uma prática cênica acessível\&quot;. Líder do Grupo de Pesquisa Teatro Flexível: práticas cênicas e acessibilidade (CNPq/UFSM) e do Laboratório de Criação (LACRI/CNPq). Pesquisadora do Teatro Flexível, investigando práticas de criação com pessoas com e sem deficiência. Coordenadora do Programa de Extensão Práticas cênicas, escola e acessibilidade. Artista da cena. Tem experiência na área de Artes, com ênfase em Teatro, atuando principalmente nos seguintes temas: teatro, processos de criação, surdez, educação, Contato Improvisação, práticas corporais, acessibilidade, cena e deficiência.
}

BRESSAN, Vanessa Corso; BERSELLI, Marcia. Processos formativos em teatro: estratégias de criação mobilizando o trânsito da atenção no processo criativo. Revista da FUNDARTE, Montenegro, p.46-62, ano 19, no 38, abril/junho de 2019.

Disponível em: http://.seer.fundarte.rs.gov.br/index.php/RevistadaFundarte/index> 28 de junho de 2019. 


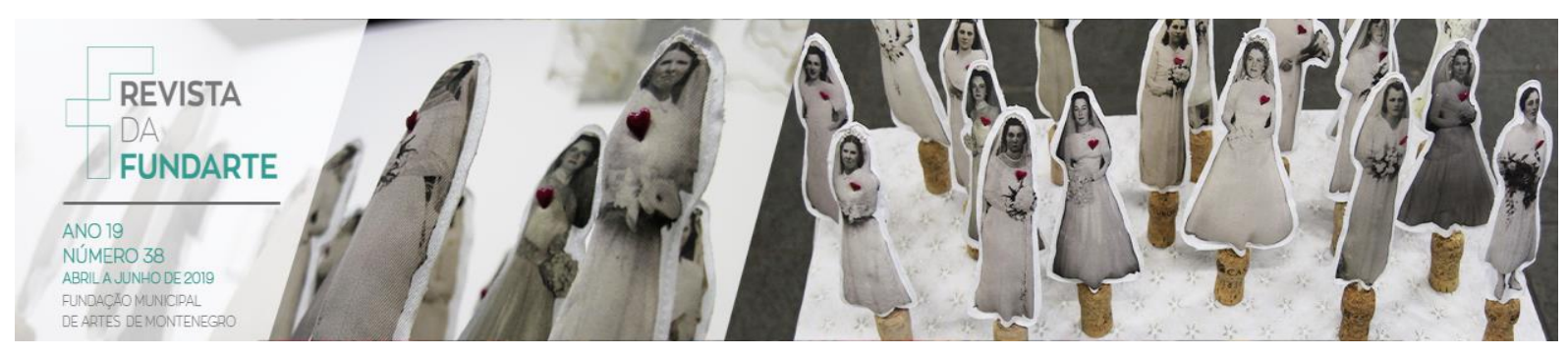

A diversidade da cena contemporânea segue alimentando artistas e pesquisadores, que buscam investigar e desvendar outros modos de criação, para além dos tradicionais, nos quais a abertura da cena para a diferença - observada tanto nos corpos quanto nas temáticas - e as relações estabelecidas entre os colaboradores ocupam papel central. Tais investigações se destacam pelo seu caráter formativo, não apenas porque costumam ocorrer nos espaços acadêmicos, mas pela busca contínua de reflexão sobre a prática, de tomada de consciência sobre seus processos, de contínuo desenvolvimento de habilidades e conhecimentos proporcionados pelos processos criativos. Nesse sentido, o presente artigo, escrito a quatro mãos, busca destacar investigações que se centraram em processos de criação desenvolvidos em espaço universitário, por um grupo misto, formado por pessoas com e sem deficiência, com e sem repertório anterior no campo do teatro. No ano de 2017 iniciou-se o período de experimentos práticos da pesquisa: Procedimentos e Práticas de Colaboração Artística Horizontal ${ }^{3}$, com enfoque nas quatro funções da cena (atuação, "espectação", encenação e design cênico $)^{4}$ como mote para o jogo. A pesquisa tem por objetivo investigar procedimentos, práticas e estratégias de criação cênica que possibilitem o desenvolvimento e a manutenção de um espaço de jogo, promovendo a criatividade compartilhada entre sujeitos com diferentes habilidades, em proposições cênicas nas quais se estimula o trânsito dos jogadores entre as diferentes funções da cena.

Em dois semestres de trabalho voltados à experimentação de estratégias de criação cênica que promovessem a flexibilidade de hierarquias entre as quatro funções da cena, entre os corpos das colaboradoras e entre seus saberes, pode-se perceber e analisar características específicas que constituem o modo de operar no

\footnotetext{
${ }^{3}$ A pesquisa é parte das investigações do Grupo de Pesquisa Teatro Flexível: práticas cênicas e acessibilidade (CNPq/UFSM). A edição de 2017 foi nomeada Procedimentos e práticas de colaboração artística horizontal: as quatro funções da cena como mote para o jogo (Bolsa PEIPSM/PRPGP/UFSM). Já em 2018, na continuidade da pesquisa, a mesma recebeu um novo subtítulo de acordo com o enfoque atual: corpos, repertórios e saberes.

4 Parte-se da definição de quatro funções primordiais da cena teatral. Segundo o teatrólogo argentino Jorge Dubatti (2008, p. 28): "Chamamos convívio ou acontecimento convivial à reunião, de corpo presente, de artistas, técnicos e espectadores em uma encruzilhada territorial cronotópica (unidade de tempo e espaço) cotidiana". Optamos por atualizar o termo "técnicos" por "design cênico", de modo a atualizar a noção compreendendo seu caráter de criação e não apenas operação técnica.
}

BRESSAN, Vanessa Corso; BERSELLI, Marcia. Processos formativos em teatro: estratégias de criação mobilizando o trânsito da atenção no processo criativo. Revista da FUNDARTE, Montenegro, p.46-62, ano 19, no 38, abril/junho de 2019.

Disponível em: http://.seer.fundarte.rs.gov.br/index.php/RevistadaFundarte/index> 28 de junho de 2019. 


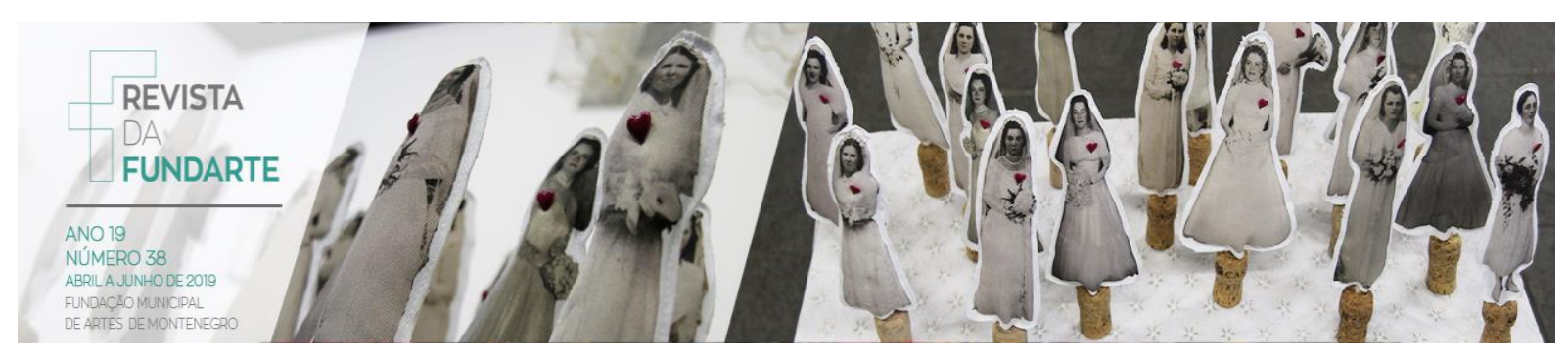

contexto em que essa pesquisa escolhe para se desenvolver. Coloca-se como central para a pesquisa, a perspectiva da ampliação do acesso aos modos de produção cênica, problematizando especializações e competências prévias. Assim, é necessário e de extrema importância que se descreva o meio no qual o estudo se desenvolve e se orienta, de outra maneira não se poderia descrever suas especificidades.

O presente artigo também se pretende como um registro e compartilhamento do que o grupo de pesquisa vem praticando e refletindo, destacando os modos como trabalhamos na prática e como buscamos a sua compreensão através de articulação teórica. Ainda, tal postura revela nossa compreensão acerca do fazer teatral, que não é considerado de um modo global, mas territorializado, ou seja, pertencente a um determinado contexto geográfico (DUBATTI, 2008). Trata-se do teatro de um grupo de pesquisa vinculado à Academia, em uma universidade localizada no interior do estado do Rio Grande do Sul. Para ampliar o reconhecimento inicial sobre as origens do grupo, nos parece necessário destacar também a maneira como o coletivo de pessoas participantes se estabeleceu, quais são os princípios do grupo e o intuito de cada estratégia utilizada.

O coletivo se estabelece pelos princípios do modo de operar dos processos colaborativos, que pressupõe a participação horizontal de todas as colaboradoras para/com 0 ato criativo. Pauta-se a horizontalidade pela proposição de que não exista uma figura detentora do poder no processo, o que não pressupõe que inexista uma figura-líder, porém, a liderança é flexibilizada e as informações são compartilhadas com as integrantes, tornando visíveis as etapas do processo e as decisões sobre o mesmo. As funções da cena existem, mas, estando relacionadas aos interesses e habilidades de cada jogadora. O que é reconfigurado nos processos que se enquadram no modo colaborativo são os interesses de cada participante, que saem da esfera da individualidade e se estabelecem pelas propostas do grupo, alcançando o caráter da coletividade. Dessa forma, estabelecemos um coletivo híbrido, composto por pessoas com e sem deficiência,

BRESSAN, Vanessa Corso; BERSELLI, Marcia. Processos formativos em teatro: estratégias de criação mobilizando o trânsito da atenção no processo criativo. Revista da FUNDARTE, Montenegro, p.46-62, ano 19, no 38, abril/junho de 2019.

Disponível em: http://.seer.fundarte.rs.gov.br/index.php/RevistadaFundarte/index> 28 de junho de 2019. 


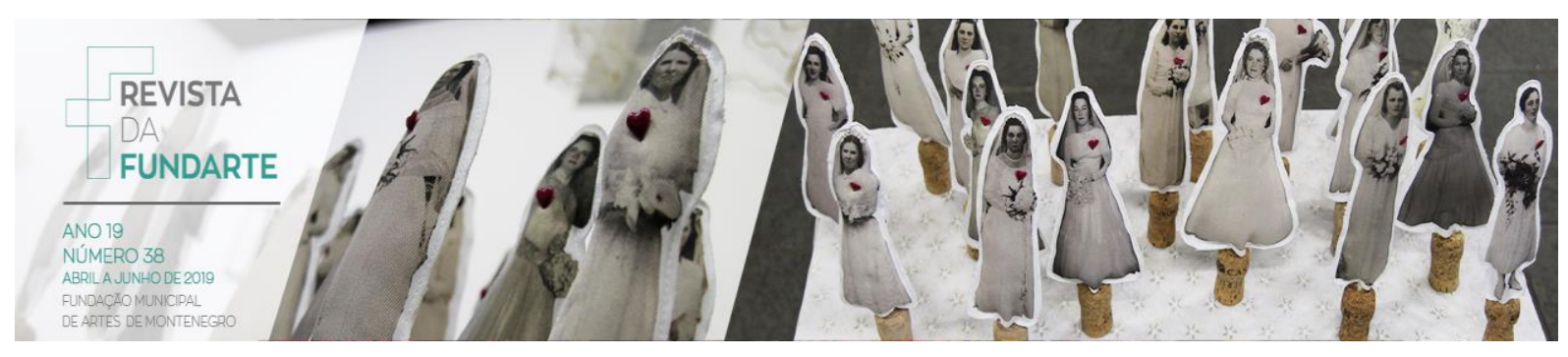

com e sem repertório prévio no campo teatral, estudantes de teatro e de outras áreas do conhecimento.

Uma das práticas de base do grupo é o Contato Improvisação, forma de dança extremamente acessível e democrática, desenvolvida por Steve Paxton junto a colaboradores, e que se concretiza através de pontos de contato físico compartilhados entre duas ou mais pessoas que se movem pelo espaço. Já o Cycles Repère é uma das estratégias de criação exercitadas, tendo em vista o compartilhamento dos princípios do modo de trabalho colaborativo. Sua proposta foi organizada por Jacques Lessard a partir dos princípios do RSVP Cycles desenvolvidos por Lawrence Halprin ${ }^{5}$. Esse procedimento tem um caráter cíclico pela forma que se constitui e que pode ser aplicado/executado. Sua estrutura é composta por quatro etapas: recursos, exploração, avaliação e representação que servem como um caminho maleável a ser percorrido durante o processo criativo, podendo, as etapas, serem ou não seguidas conforme a ordem indicada (BEAUCHAMP; LARRUE, 1990).

Um segundo procedimento utilizado são as Funções flutuantes, proposta criada por Marcia Berselli e Natália Soldera (2014), aqui abordada com intuito criativo pedagógico de desenvolver as habilidades das participantes nas quatro funções da cena. Esse procedimento promove o desenvolvimento das competências de cada participante nesses espaços por fundar-se na demarcação espacial das quatro funções, sendo que, para iniciar o jogo cada uma das participantes deve ocupar uma das demarcações espaciais, entendendo que duas ou mais pessoas podem compartilhar um mesmo espaço de função, mas nenhum deles deve ficar vazio. Ao longo do desenvolvimento da proposta, as jogadoras podem se deslocar para o espaço de outras funções e experienciá-las. Só existe a necessidade da verbalização desse deslocamento, como por exemplo: $X$ da atuação para a encenação. Ou seja, ocorre o deslocamento de alguém que ocupava a função da

\footnotetext{
${ }^{5}$ Lawrence Halprin, em 1968, sistematiza a metodologia RSVP - ciclos de respostas (Répondez, s'il vous plâit), em uma relação estreita com Anna Halprin, performer e coreógrafa. Essa sistematização envolve quatro etapas de desenvolvimento. Cada uma delas se refere a uma das letras das siglas que dão nome ao ciclo.
}

BRESSAN, Vanessa Corso; BERSELLI, Marcia. Processos formativos em teatro: estratégias de criação mobilizando o trânsito da atenção no processo criativo. Revista da FUNDARTE, Montenegro, p.46-62, ano 19, no 38, abril/junho de 2019.

Disponível em: http://.seer.fundarte.rs.gov.br/index.php/RevistadaFundarte/index> 28 de junho de 2019. 


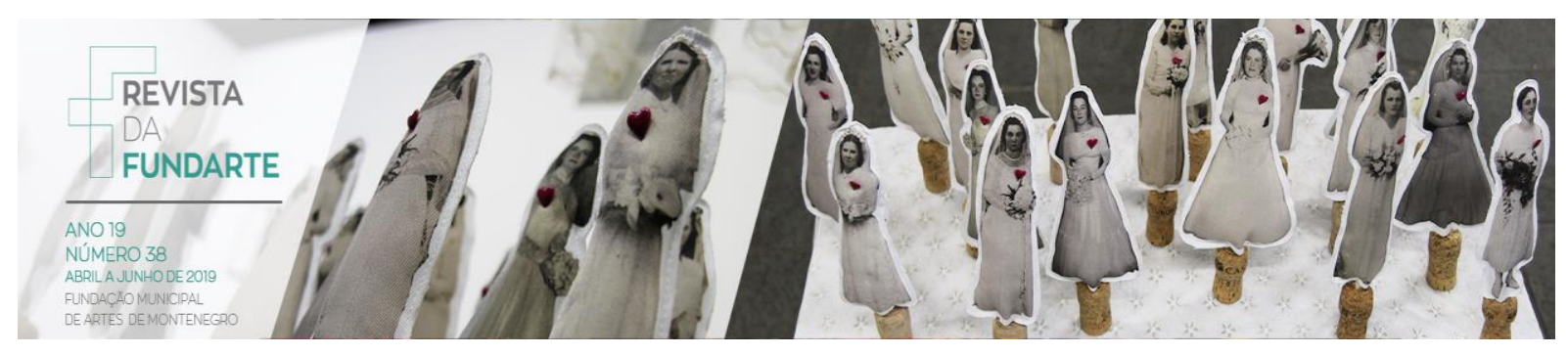

atuação e passou a ocupar a função da encenação. Dessa maneira, percebe-se que constantemente esse trânsito é realizado pelas participantes, acarretando um fluxo contínuo de experimentações de cada indivíduo em todos os espaços.

Este fluxo contínuo, alcançado por meio desse procedimento, gera grande importância no desenvolvimento das proposições cênicas e competências das participantes. A constante transição entre os espaços cênicos acarreta na experimentação das habilidades individuais das participantes e no seu desenvolvimento durante o executar das propostas. As diferenças entre os corpos das colaboradoras e seus repertórios se caracterizam como potências criativas, posto que tentamos entender a relação do indivíduo com si próprio, com o meio e com os outros indivíduos de uma maneira particular. Inicialmente, ou fora do contexto dessa pesquisa, as limitações corporais de uma pessoa podem ser vistas como um impedimento, uma condição que restringe o indivíduo a possibilidades reduzidas, mas aqui escolhe-se olhá-las por outra perspectiva, aquela que vê outras alternativas e está decidida a descobrir a liberdade dentro das limitações corporais de cada um. Estamos dispostas a promover o uso criativo da imaginação das participantes, fazendo com que sejam encontradas novas formas de desenvolver o trabalho com o reconhecimento dos limites de cada uma. Entendemos também a noção de limitação de uma maneira expandida. Os limites não estão restritos às participantes com deficiência física, facilmente identificados pelo olhar, mas concernem a todas as participantes de diferentes maneiras, e não só fisicamente.

Aprofundando a reflexão sobre as limitações, é possível traçar um paralelo com o discurso de Pascal Chabot, citado por Neto, ao tratar da individuação: "a individuação é transcendental, ela diz respeito às estruturas formais do sujeito" (CHABOT apud NETO, 2017, p. 212), já a individualização "é o modo como cada um atualiza e estiliza a individuação, a partir da sua história e preferências" (NETO, 2017 , p. 212). Só entendemos que uma pessoa tem limitações porque ela não atende à individuação, à estrutura, ao modo padrão de realizar um movimento. Então ela encontra a individualização desse movimento, que é o modo como ela adapta a individuação às características que a constituem como indivíduo. E é

BRESSAN, Vanessa Corso; BERSELLI, Marcia. Processos formativos em teatro: estratégias de criação mobilizando o trânsito da atenção no processo criativo. Revista da FUNDARTE, Montenegro, p.46-62, ano 19, no 38, abril/junho de 2019.

Disponível em: http://.seer.fundarte.rs.gov.br/index.php/RevistadaFundarte/index> 28 de junho de 2019. 


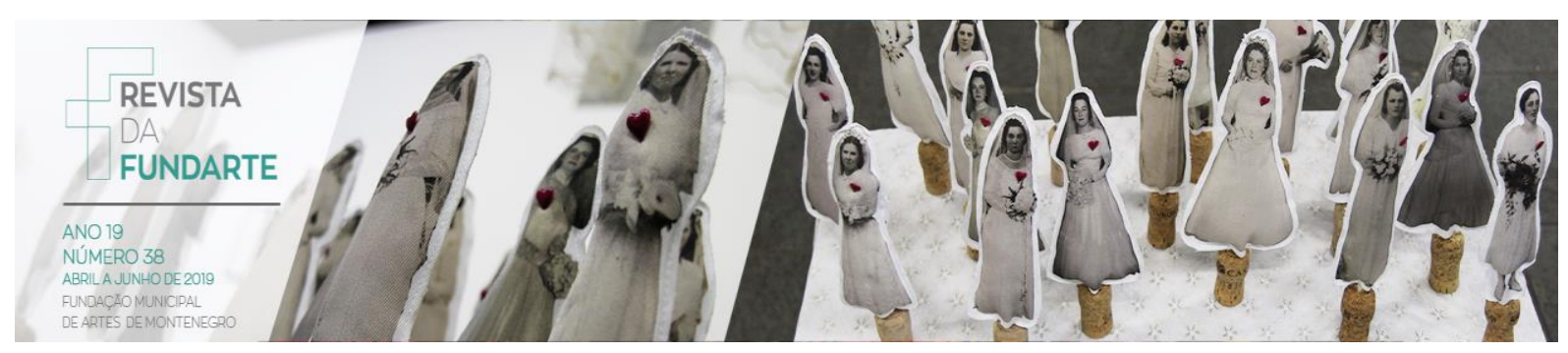

exatamente por isso que faz-se o uso da imaginação criativa. Enquanto os indivíduos que são capazes de executar os padrões existentes pela individuação continuam a reproduzi-los, aqueles que não respondem dessa maneira descobrem novas soluções.

A descoberta de novas soluções, em nosso projeto, está interligada a abordagens não dramáticas da cena. No processo de criação do grupo, a relação a ser buscada não permanece em um nível dramático. Lehmann (2003) afirma que entre a série de formas dramáticas existentes, sendo algumas muito diferenciadas, entre elas, há uma única coisa em comum: terem atrás de si uma história, que é o teatro dramático. Assim, na abordagem criativa operada pelo grupo, não há a necessidade de manter um vínculo com o teatro dramático - da decorrência de fatos, da existência de uma lógica ou desencadeamento de ações por causa e consequência, de um início, meio e fim aristotélico. Essa relação pode ser uma negação dos jogos propostos, pode ser uma quebra que não atenda às expectativas de narrativas, que muitas vezes costumamos criar. Podendo, assim, ir ao encontro de propostas vinculadas ao teatro não-dramático, sobre o qual viemos aprofundando alguns entendimentos através de leituras e reflexões em nossos encontros teóricos.

\section{O jogo com as funções revelando processos de ensino-aprendizagem}

Entendendo esse local de trabalho com as funções e percebendo o contexto em que elas estão inseridas, pensando-as colaborativamente, constata-se que efetivamente elas são mote para despertar nosso olhar para o jogo. Quando se está trabalhando com as funções flutuantes, todos os espaços são promotores do jogo, tendo em vista suas constantes ocupações e interferências. Diferentemente de um processo que se funda na ideia tradicional de encenador, que é considerada a pessoa responsável por determinar e delimitar a cena sendo a única promotora de modificações e indicações ao ator. Aqui, o encenador não é o único a estimular os demais e também não se limita à figura de uma única pessoa, a técnica, a atuação e a "espectação" também são espaços que ganham potência propositora. Todas as funções estão em jogo umas com as outras e dessa forma se retroalimentam pelos

BRESSAN, Vanessa Corso; BERSELLI, Marcia. Processos formativos em teatro: estratégias de criação mobilizando o trânsito da atenção no processo criativo. Revista da FUNDARTE, Montenegro, p.46-62, ano 19, no 38, abril/junho de 2019.

Disponível em: http://.seer.fundarte.rs.gov.br/index.php/RevistadaFundarte/index> 28 de junho de 2019. 


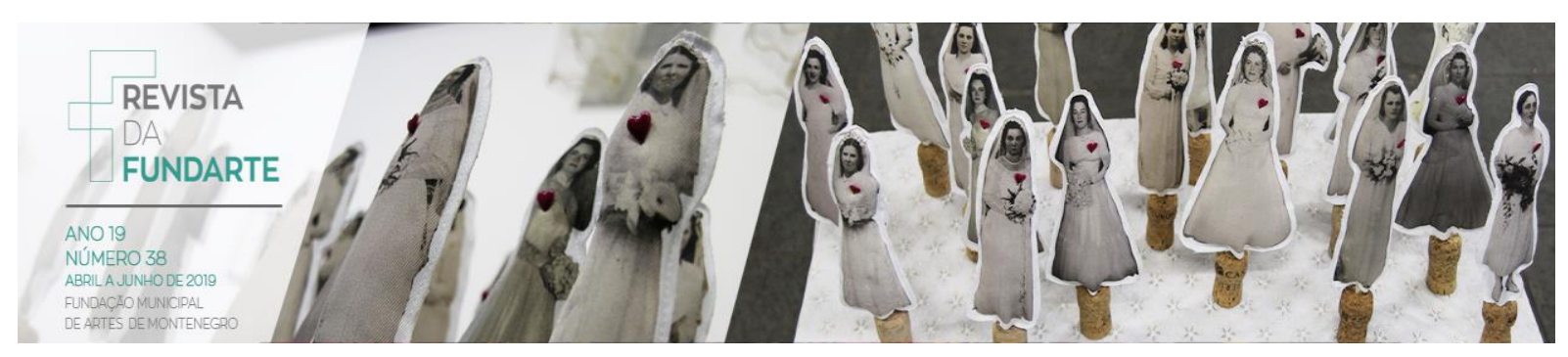

olhares de quem as ocupa para promover o jogo. Os estímulos não têm efeito em um único ponto, eles reverberam entre todas as jogadoras, fazendo com que, por exemplo, a técnica estimule uma nova indicação a ser dada pela encenação ou então dois estímulos possam ser lançados juntos para a atuação e nisso quem ocupa esse espaço terá de se relacionar com o que lhe é proposto.

As funções, por si só, são disparadoras de ação na improvisação. Ao ocupar uma determinada função, a jogadora é incutida a disparar ações relacionadas às competências daquele espaço. Dessa maneira, existe a constante busca por respostas, aquilo que as funções nos propõem a olhar. Ao responder, a jogadora exercita e amplia seu repertório em relação à função ocupada, ou seja, desenvolve seu processo de aquisição de competências necessárias para operar na função. $O$ desenvolvimento de competências técnicas não ocorre, assim, separado do momento de criação, mas durante as improvisações e composições.

Dada essa estrutura, é possível afirmar que compomos um organismo que se mantém vivo por simbiose, pela associação dos conhecimentos, competências e habilidades de cada indivíduo, que se relacionam em conjunto e compartilham experiências e aprendizados. Estes últimos são assimilados de uma forma não tradicional e verticalizada (elocução - receptor), mas pela experimentação prática e visualização da ação do outro e de sua reverberação no experimento. Esse modo de entender os processos formativos e criativos destaca uma perspectiva que permeia práticas cênicas e estratégias de criação em que se reconhece uma flexibilidade na relação de instrumentalização dos conteúdos a serem desenvolvidos. Lisa Nelson, por exemplo, performer e bailarina norte-americana envolvida no movimento pós modernista da dança, indica uma compreensão sobre a prática (no caso específico, sua pesquisa Tuning Scores) em que a própria prática vai se modificando naturalmente através da relação entre as pessoas que praticam, sem a necessidade de estabelecer uma pedagogia. "O corpo tem todos os conhecimentos, não precisa e não tem uma forma certa de mover"6.

\footnotetext{
${ }^{6}$ Material advindo de anotações de Marcia Berselli durante o "Encontro prático com Lisa Nelson", realizado no Atelier Dudude, em Brumadinho/MG, em abril de 2014.

BRESSAN, Vanessa Corso; BERSELLI, Marcia. Processos formativos em teatro: estratégias de criação mobilizando o trânsito da atenção no processo criativo. Revista da FUNDARTE, Montenegro, p.46-62, ano 19, no 38, abril/junho de 2019.

Disponível em: http://.seer.fundarte.rs.gov.br/index.php/RevistadaFundarte/index> 28 de junho de 2019.
} 


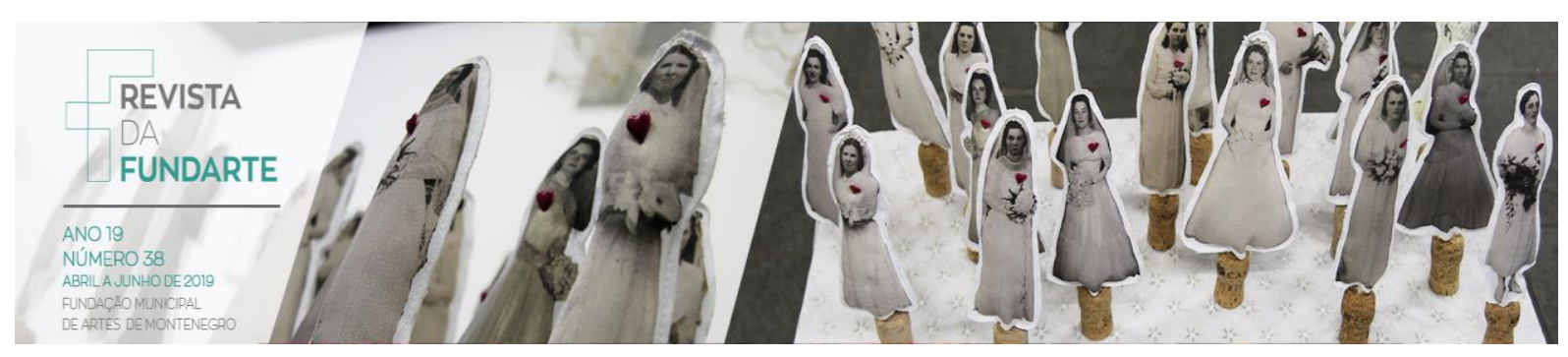

Entretanto, enquanto processo formativo, há também a presença de obstáculos. Percebemos, por exemplo, a existência de dificuldades distintas às outras funções abordadas quando operamos com o design cênico, tendo em vista a falta de repertório anterior das participantes. Ao mesmo tempo, entendendo o que Nelson fala sobre a modificação natural da prática, constatamos que a formação anterior ao jogo não é necessária, justamente pelas relações que se estabelecem no espaço de criação e por ele próprio fornecer material para instrumentalizar as participantes a partir dos recursos disponíveis. Dessa maneira vislumbramos a perspectiva de formação que não está focada em resultados específicos, mas em adquirir competências a partir da ampliação do repertório das participantes desenvolvido nos processos criativos através do jogo. Assim, os obstáculos tornamse estímulos para que as participantes encontrem sua resolução através da própria prática.

Lisa Nelson (2003) centra sua pesquisa criativa nos modos como cada sujeito organiza seu próprio movimento. Compartilhando desse interesse de Nelson em entender os modos de organização de cada indivíduo, percebe-se que a atenção de cada colaboradora dentro dessa pesquisa se organiza de maneira distinta e os espaços de criação são diretamente influenciadores dessa organização, por exemplo: as funções geram grande influência àquilo que direcionamos a nossa atenção no ato criativo porque elas propõem para quem as ocupa o que devem perceber naquele momento.

A partir do instante que nosso interesse migra para outro ponto de percepção e começamos a criar uma tensão com esse novo ponto ao qual queremos responder, nos deslocamos intuitivamente à função que nos imbui de olhar para ele, que é responsável por aquele aspecto do processo. Berselli faz alusão ao Tuning Scores para destacar esse sistema de retorno:

$\mathrm{Na}$ pesquisa Tuning scores, Lisa Nelson busca uma abordagem do movimento com uma grande importância para a auto-observação. Levando cada bailarino a perceber suas próprias estratégias de movimento, há a possibilidade de o bailarino reverter o que achava ser bom para si mesmo.

BRESSAN, Vanessa Corso; BERSELLI, Marcia. Processos formativos em teatro: estratégias de criação mobilizando o trânsito da atenção no processo criativo. Revista da FUNDARTE, Montenegro, p.46-62, ano 19, no 38, abril/junho de 2019.

Disponível em: http://.seer.fundarte.rs.gov.br/index.php/RevistadaFundarte/index> 28 de junho de 2019. 


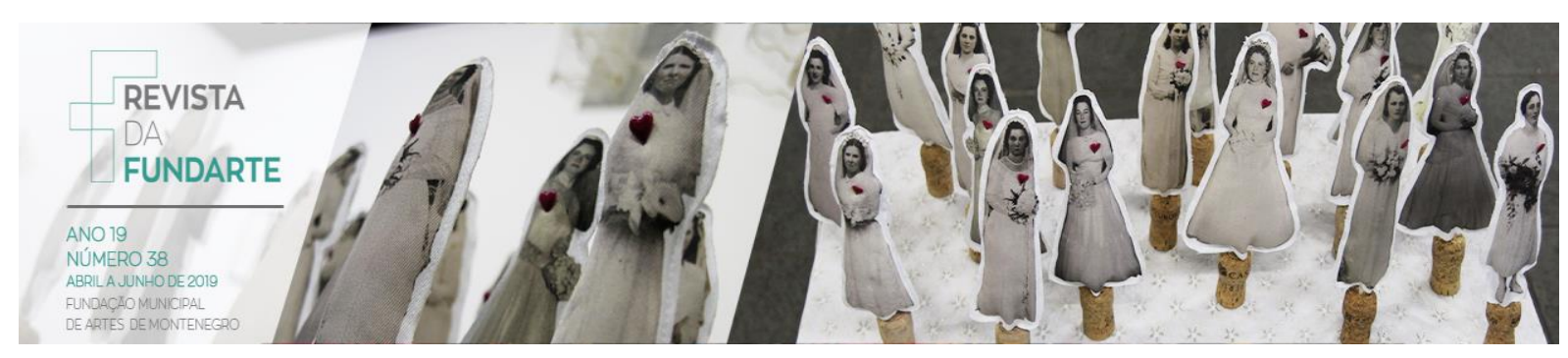

Uma proposta para interrogar como "vivo no meu corpo" e como "organizo os meus movimentos" em "um sistema de retorno, de feedback, sua ação sempre tem uma consequência que você mesmo pode perceber" .(BERSELLI, 2014, p. 106).

Focamos nosso sentido naquilo que as funções propõem em seu espaço e no que o jogo que se estabelece começa a propor e, a partir deste momento, estamos em constante adaptação para ocupar o lugar/as funções a qual estamos focados. Os movimentos/ações, entre as colaboradoras e as funções, não acontecem individualmente, mas, sim, em reciprocidade. Cada indivíduo coloca questões e apresenta problemas a serem resolvidos junto aos outros.

\section{O trânsito da atenção no processo criativo}

A partir do feedback de espectadores convidados para o compartilhamento de uma experiência cênica - resultante da organização de partituras sintéticas ${ }^{7}$-, bem como das primeiras percepções obtidas como resultantes da investigação acerca do trânsito da atenção, os entendimentos sobre a atenção neste contexto foram sendo formatados. Inicialmente buscava-se entender qual a potência desse trânsito para o processo criativo, ou mesmo, se existia alguma potência, tendo em vista o que seria percebido a partir da prática.

Em consequência da visibilidade adquirida pelas funções flutuantes, do fluxo entre as funções da cena, alguns entendimentos sobre o modo de operar aqui implicado surgiram em relação ao primeiro recorte, sendo um deles: a atenção que não está ligada somente a um ponto, mas está relacionada a todos as jogadoras e funções, gerando uma constante manutenção do jogo durante o processo criativo. Isso evidencia que o estado de jogo ${ }^{8}$ das participantes também está em constante

\footnotetext{
7 No Cycles Repère, as partituras sintéticas são resultantes da fase inicial de exploração de recursos por improvisações, considerada a fase das partituras exploratórias. A partir delas são feitas anotações e selecionados os materiais a serem desenvolvidos posteriormente, dando origem às partituras sintéticas.

8 Por "estado de jogo", compreendemos o estabelecimento da dimensão ficcional da cena, sem estarmos restritos ao que tradicionalmente tem se denominado teatro dramático, mas na compreensão do espaço de atuação enquanto espaço que comporta o jogo, a atmosfera instaurada em cena pela relação entre criadores, elementos e espaço, instaurando uma dimensão para além do real imediato.
}

BRESSAN, Vanessa Corso; BERSELLI, Marcia. Processos formativos em teatro: estratégias de criação mobilizando o trânsito da atenção no processo criativo. Revista da FUNDARTE, Montenegro, p.46-62, ano 19, no 38, abril/junho de 2019.

Disponível em: http://.seer.fundarte.rs.gov.br/index.php/RevistadaFundarte/index> 28 de junho de 2019. 


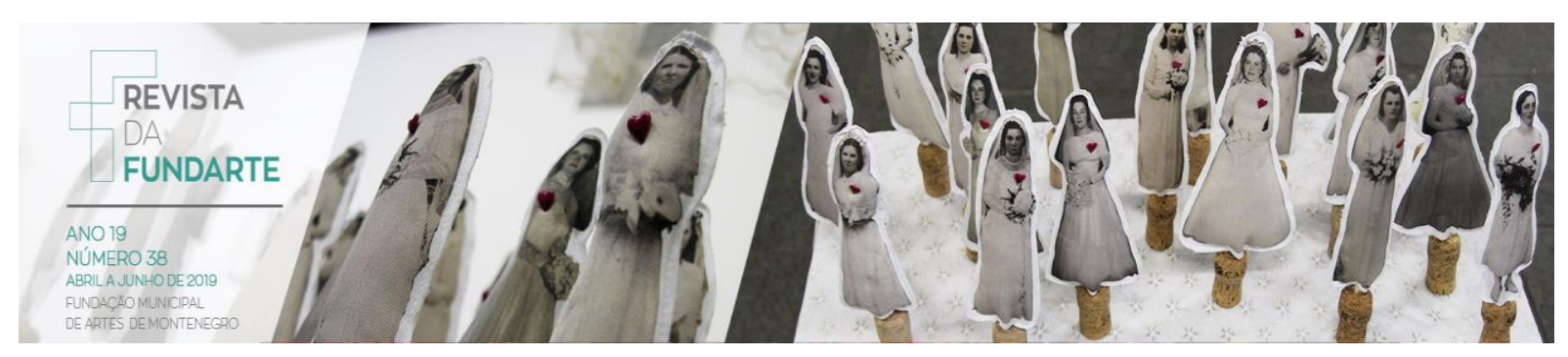

manutenção, justamente pelo fato de a jogadora ter de se adaptar e relacionar a todos os recursos do processo.

Em meio a essa procura e ao alcance de algumas indicações, surge o questionamento sobre ser mesmo a atenção que deve ser estudada/analisada, sobre o que mais deve ser lido sobre ela para esclarecer essa dúvida e por meio de quais definições a entendemos.

O direcionamento da atenção no trabalho do ator é ponto de destaque no trabalho de importantes expoentes do teatro, sendo evidenciado em Stanislavski (2000) através, por exemplo, dos círculos de atenção, e em Grotowski traduzido (ou ampliado) para a noção de contato (GROTOWSKI, 2010, p. 155). Em ambos os casos, a atenção está vinculada a objetivos do ator, focalizando todo o seu ser a pontos específicos de modo a estimular reações direcionadas. No Contato Improvisação, prática de base do grupo de pesquisa, a atenção é competência fundamental que permite a continuidade de movimentos improvisados proposta na prática de dança.

Atenção é organização do corpo de alguma forma, por força de circunstâncias ou objetivos, para lidar com algo. Entretanto, a atenção no fluxo da dança de Contato não traz o propósito de estender o raio de decisões a ponto do controle excessivamente voluntário dos movimentos. A atenção aqui deve estar mais envolvida com o testemunho sobre o fluxo do que com o seu controle. (SILVA, 2014, p. 103).

Ou seja, não se trata de realizar uma reflexão aprofundada a cada tomada de decisão, nem de uma busca por nomear o que está acontecendo, mas de focalizar a percepção no momento presente de modo a reagir e, com isso, provocar a manutenção do estado de jogo. Através da proposta das Funções flutuantes, o que se observa é que a atenção das jogadoras é direcionada para a cena ao mesmo tempo, porém com objetivos diversos que estão conectados às funções ocupadas no momento atual. Assim, a atenção de todas converge para as ações no espaço delimitado da atuação, porém cada colaboradora opera com objetivos específicos que influenciam suas respostas ao jogo. Ainda, sabendo da possibilidade de flutuar de uma função a outra, a opção de operar em outro espaço que não o atualmente

BRESSAN, Vanessa Corso; BERSELLI, Marcia. Processos formativos em teatro: estratégias de criação mobilizando o trânsito da atenção no processo criativo. Revista da FUNDARTE, Montenegro, p.46-62, ano 19, no 38, abril/junho de 2019.

Disponível em: http://.seer.fundarte.rs.gov.br/index.php/RevistadaFundarte/index> 28 de junho de 2019. 


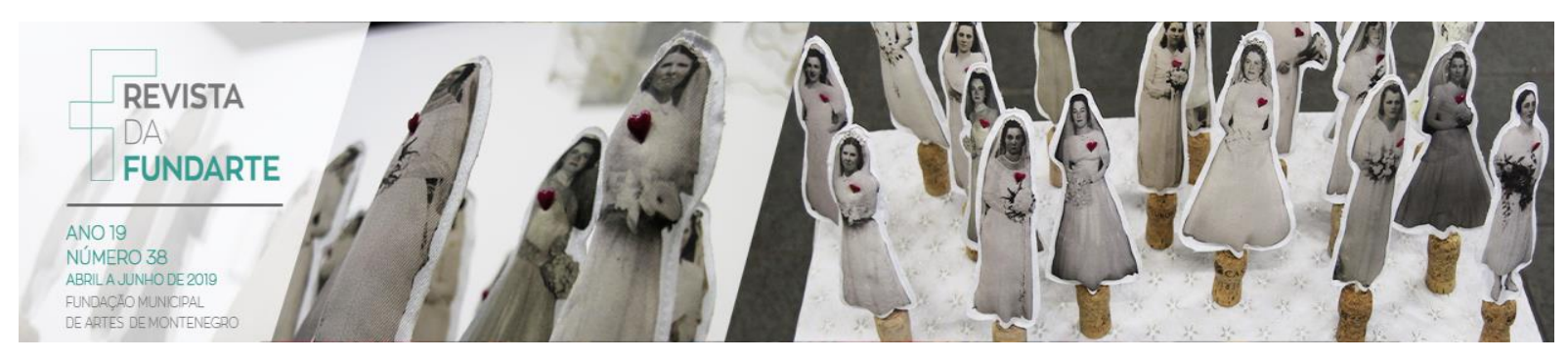

ocupado deixa as jogadoras em uma espécie de suspensão das outras funções que ficam em segundo plano e que podem passar ao primeiro plano rapidamente, caso a resposta definida assim o exija. É possível ponderar que o objetivo geral das jogadoras seja a manutenção do jogo, enquanto que os objetivos específicos sofrem alterações constantes, de acordo com as propostas nascidas do próprio jogo.

Sobre a organização da atenção, podemos ir ao encontro do que Lisa Nelson, nas palavras de Neto, denomina como atenciografia: "a atenciografia é o mapeamento sensível da atenção como suporte da imaginação do corpo que se posiciona no espaço e se prepara para responder aos estímulos dos elementos através dos quais se move" (NELSON apud NETO, 2017, p. 206). Em nosso caso, podemos entender como elementos promotores de estímulos às participantes, os recursos sensíveis ${ }^{9}$, as funções e o acontecimento. Dessa forma, a atenção das participantes está constantemente em movimento, por consequência dos diversos estímulos citados, que promovem sua organização e reorganização, destacando a relação entre a atenção e a imaginação.

\section{Responsabilidades do espectador}

O lugar do espectador nessa prática pode ser compreendido a partir de Lehmann (2003, p. 12), quando, ao tratar do Teatro pós-dramático, expõe: "nesse tipo de apresentação, o espectador é imbuído de uma responsabilidade por aquele processo. E, ao mesmo tempo, é parte do espetáculo". Obviamente o que ele diz está relacionado a outro fazer, mas aproximamos dessa prática pela maneira como trabalhamos, por atribuirmos responsabilidades explícitas ao espectador, mas não necessariamente verbalizadas. No caso da citação, ele expõe uma situação em que o público vivencia a experiência de uma performance, da qual poderia intervir da maneira que quisesse, fazendo parte do acontecimento. Entendemos que, em nossa prática, quem ocupa a função da "espectação" está continuamente se relacionando com o acontecimento. Dessa maneira, estamos constantemente imbuídos da

\footnotetext{
9 São as fontes de diversas naturezas que impulsionam a criação e que cada participante sugere no início do processo. Elas devem tocar o criador, convocando-o para o jogo, e podem ser, por exemplo, um som, uma performance, um objeto, um texto.
}

BRESSAN, Vanessa Corso; BERSELLI, Marcia. Processos formativos em teatro: estratégias de criação mobilizando o trânsito da atenção no processo criativo. Revista da FUNDARTE, Montenegro, p.46-62, ano 19, no 38, abril/junho de 2019.

Disponível em: http://.seer.fundarte.rs.gov.br/index.php/RevistadaFundarte/index> 28 de junho de 2019. 


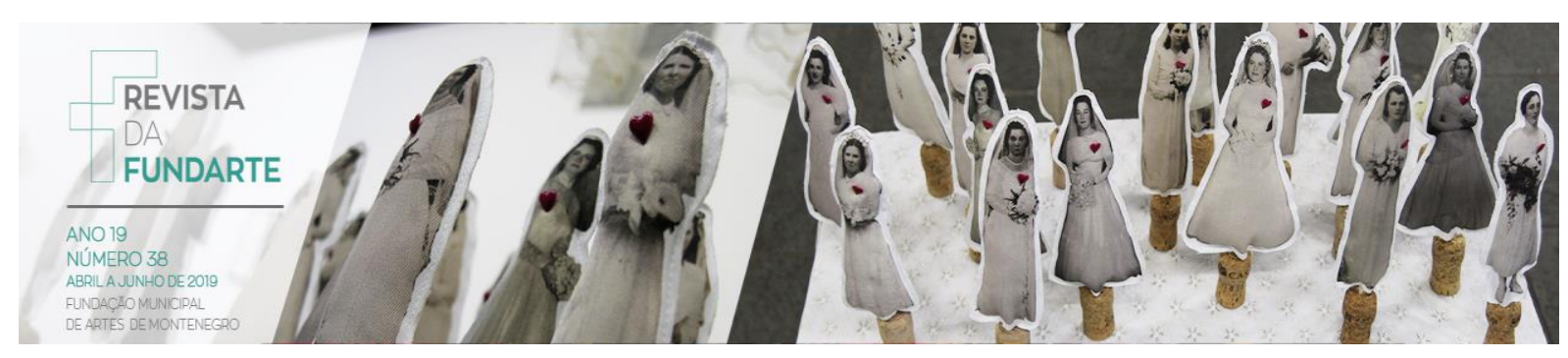

responsabilidade pelo desenvolvimento do processo e da criação e devemos estar disponíveis a isso.

Tal disponibilidade por parte do espectador é criada pela forma que constituímos as práticas, visto não ser uma competência visualizada em qualquer processo, da mesma maneira que o espectador não necessariamente é ou se sente responsável pelo processo quando inserido em outro contexto. No teatro tradicional, dificilmente entende-se a "espectação" como uma função dentro do processo criativo, estando restrito à existência de somente duas funções primordiais: a atuação e a encenação. Tendo em vista que no teatro dramático tradicional existe uma série de convenções que fazem com que não haja espaço para o espectador ativo. $\mathrm{Na}$ experiência dessa forma teatral o público está condicionado a visualizar a representação dos atores como uma justaposição da vida, ignorando o fato de se estar em uma sala de teatro, entendendo a história que ali se passa como real e instantânea e não como a representação de um universo ficcional. Nesse sentido, a representação depende da empatia dos espectadores em relação ao que está sendo apresentado, sendo que a teatralidade depende da abstração por parte dos espectadores ${ }^{10}$. Por outro lado, evidenciar os mecanismos da cena é uma característica do trabalho de importantes expoentes do teatro ocidental, tais como Meyerhold e Brecht. Apesar das diferenças em relação às estéticas propostas, é importante ter em vista que destacar os aspectos da teatralidade em oposição à manutenção da ilusão não é uma proposta nova.

Ainda, em relação ao espectador, e a sua importância na participação dos processos criativos, é importante destacar que os modos de observar, de se colocar em relação a um objeto que se dá a ver, alteram o que será visto. Para a diretora e pedagoga Anne Bogart (2011, p. 77),

A física quântica nos ensina que 0 ato de observação altera a coisa observada. Observar é perturbar. "Observar" não é um verbo passivo. Como diretora, aprendi que a qualidade de minha observação e atenção pode determinar o resultado de um processo. Nas condições corretas, a observação e a atenção do público podem afetar significativamente a

\footnotetext{
${ }^{10} \mathrm{~A}$ impossibilidade de abstração compromete a instauração da teatralidade enquanto um contexto diferenciado do acontecimento cênico (FÉRAL, 2003).
}

BRESSAN, Vanessa Corso; BERSELLI, Marcia. Processos formativos em teatro: estratégias de criação mobilizando o trânsito da atenção no processo criativo. Revista da FUNDARTE, Montenegro, p.46-62, ano 19, no 38, abril/junho de 2019.

Disponível em: http://.seer.fundarte.rs.gov.br/index.php/RevistadaFundarte/index $>28$ de junho de 2019. 


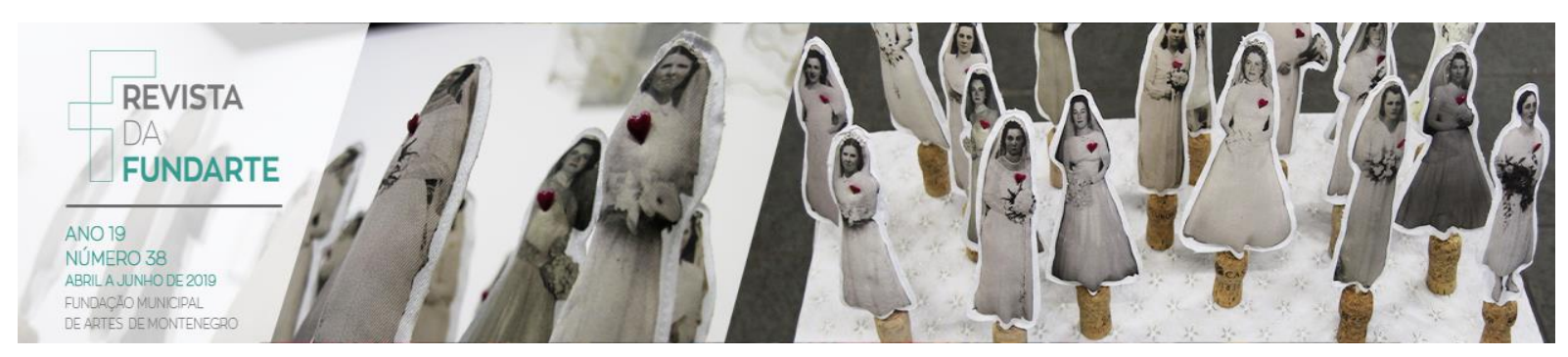

qualidade da interpretação de um ator. Os atores respondem ao poder de observação das plateias. É o ciclo contacto/resposta no centro da apresentação ao vivo que torna o fato de estar ali presente algo tão extraordinário.

Bogart afirma que o contato/resposta entre o espectador e o espetáculo é extraordinário no momento da representação, então, entendendo que essa relação se estabelece em nossa prática, já no processo criativo ${ }^{11}$, ela se caracteriza como uma grande potência a ser pensada e mantida. Novamente indo ao encontro de Bogart, a potência dessa relação acontece pela qualidade de observação e atenção, já discutida nesse artigo, que o espectador disponibiliza ao ato criativo e da qual está imbuído a assumir efetivamente. Anne Bogart (2011) continua a falar sobre o ato de observar e diz que ele é capaz de alterar o que está sendo observado. Ou seja, existindo a constante observação por parte de todas as funções dentro desse processo, mas pensando ainda, pontualmente, na função da "espectação", esta que é destinada, especificamente, ao ato de observar, pode-se entendê-la como fundamental à promoção de alterações.

\section{Conclusões parciais}

Em relação à atenção, é possível concluir que os objetivos específicos de cada colaboradora sofrem alterações que estão diretamente ligadas à organização da atenção de cada jogadora para/com o processo. Tal organização tem relação direta com as funções, tendo em vista que o interesse das participantes é cativado por aspectos diferentes dentro de cada experimentação, gerando movimentos e ações distintos uns dos outros. Reafirma-se, assim, o aspecto da manutenção do estado de jogo pela atenção das participantes e por aquilo que thes é despertado a partir do momento que estabelecem uma linha de tensão entre um objeto/ação ou entre pessoas. Essa tensão está relacionada com a leitura do que está em nosso entorno, conforme destaca Lisa Nelson (2003, p. 01-02):

\footnotetext{
${ }^{11}$ Vale destacar que nos exercícios de criação desenvolvidos, sempre há a presença de jogadoras enquanto espectadoras, ou seja, o processo já destaca a presença ativa de tal função.

BRESSAN, Vanessa Corso; BERSELLI, Marcia. Processos formativos em teatro: estratégias de criação mobilizando o trânsito da atenção no processo criativo. Revista da FUNDARTE, Montenegro, p.46-62, ano 19, no 38, abril/junho de 2019.

Disponível em: http://.seer.fundarte.rs.gov.br/index.php/RevistadaFundarte/index> 28 de junho de 2019.
} 


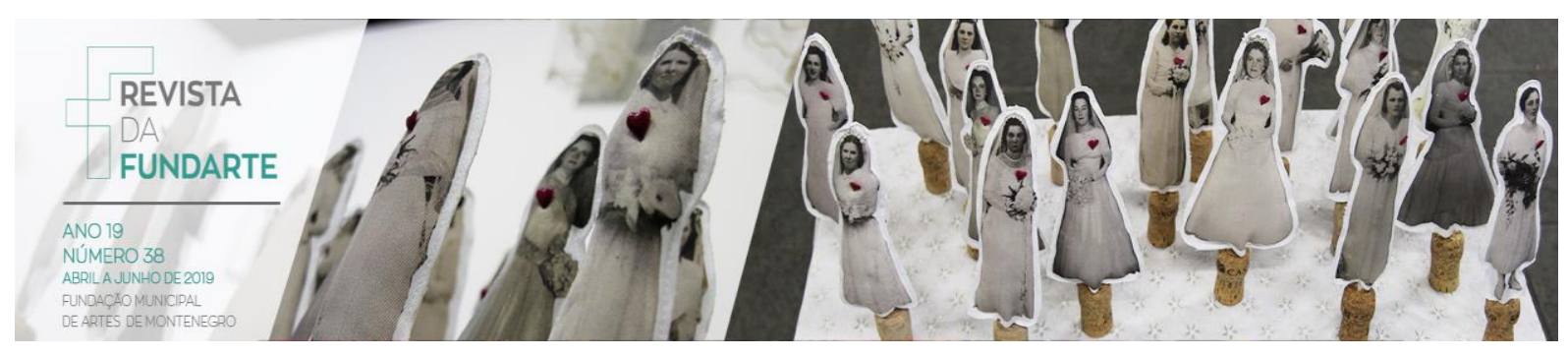

Somos especialistas em movimento de leitura. Nós dependemos da leitura dos detalhes para a nossa sobrevivência. [...] Nós até mesmo lemos ações antes que elas apareçam. Com um olhar imperceptível, podemos sentir que alguém a quem não queremos que nos veja está prestes a virar para nos encarar. Antes que nós saibamos, nós compomos nosso corpo para ser invisível, ou compomos nossos olhos para estar em outro lugar na chance de que vamos ser ignorados. Nós estamos constantemente recompondo o nosso corpo e nossa atenção em resposta ao meio ambiente, para as coisas conhecidas e desconhecidas. Esta dança interna é uma improvisação - uma leitura mais básica e responde aos scripts do meio ambiente. É o diálogo do nosso corpo com a nossa experiência.

Estamos atentas ao momento presente. Todos os dias participamos de um novo experimento. A atenção, imaginação e emoção estabelecem a relação do sujeito com o mundo a partir da sua orientação no espaço e sua organização corporal em movimento e no movimento (NETO, 2017). Assim, a orientação no espaço, especificamente com a presença das quatro funções, estabelece a relação que o sujeito terá para com o experimento.

O acontecimento se dá no tempo presente a partir da relação com os recursos sensíveis. Esses últimos podem reaparecer ou serem anulados nas retomadas das cenas. Dessa forma, existe a necessidade de contínua atenção para que a reação ao que está sendo criado seja efetiva, visto que, segundo Bogart (2011, p. 79):

A qualidade de atenção que se oferece no ensaio é a chave para um processo fecundo. O ensaio é um microcosmo do relacionamento de atenção oferecido de forma ampliada pelo público. É o local onde existe a possibilidade de arrebatamento.

Sobre as retomadas, entende-se que não é necessário que elas sejam feitas como na primeira vez e que existe uma margem para o surgimento de novas propostas. Sabendo que não queremos simplesmente reproduzir o que já foi feito anteriormente, o mais importante é a retomada do jogo entre as participantes. Tal possibilidade/necessidade de retomar o jogo está vinculada com a espontaneidade que se mantém ao longo das retomadas das composições. Isso se dá pelo fato de não estarmos interessadas em recriar acontecimentos/circunstâncias/imagens iguais

BRESSAN, Vanessa Corso; BERSELLI, Marcia. Processos formativos em teatro: estratégias de criação mobilizando o trânsito da atenção no processo criativo. Revista da FUNDARTE, Montenegro, p.46-62, ano 19, no 38, abril/junho de 2019.

Disponível em: http://.seer.fundarte.rs.gov.br/index.php/RevistadaFundarte/index> 28 de junho de 2019. 


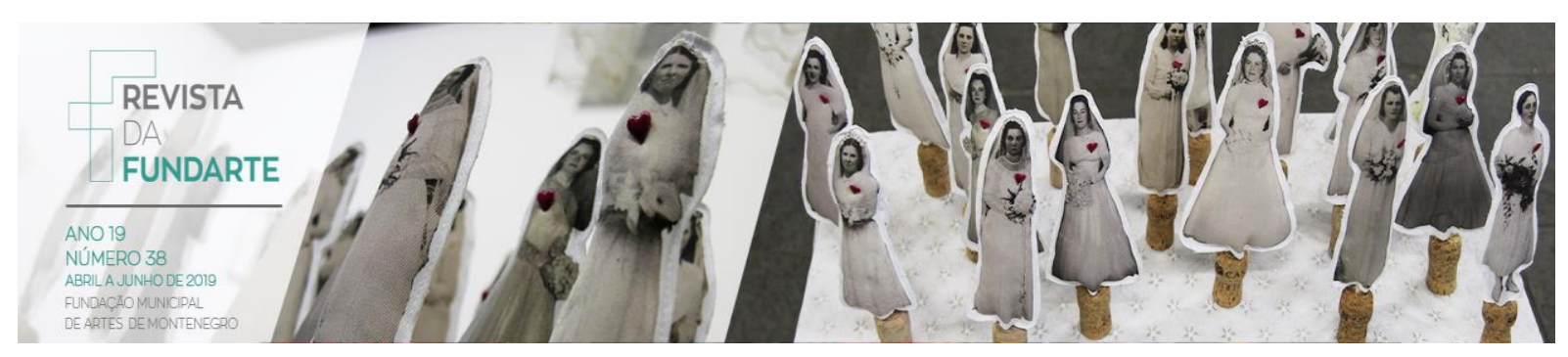

às da primeira experimentação. Não estamos limitadas pela forma das ações ou preocupadas em atingir sempre o mesmo estado e intenção.

Conclui-se, por fim, que no contexto em que esta pesquisa está sendo desenvolvida, privilegiando o coletivo em detrimento ao individual, as diferenças de corpos, habilidades e repertórios dos participantes são compreendidas enquanto argumento potente para a criação. A pesquisa, assim, destaca o aperfeiçoamento coletivo de saberes, a partilha de vivências e a disseminação de práticas teatrais que entendam o indivíduo, com todas suas particularidades, enquanto agente mobilizador do processo de criação.

O eixo teórico da pesquisa é fundamental, tendo em vista os entendimentos que são compreendidos através da escrita e compartilhamento de processos criativos. Dessa forma, destacamos a necessidade de reflexão sobre as práticas realizadas e de partilha dos escritos advindos de tais práticas. O processo criativo em teatro, sempre um espaço formativo, é efêmero e, de modo geral, acontece em pequenos contextos de salas de ensaio ou de aula. Assim, a escrita é a forma encontrada para que a pesquisa desenvolvida - híbrida de práticas, teorias e reflexões - possa chegar a terceiros e apontar possíveis caminhos, da mesma forma que em muitos momentos a leitura de pares iluminou nosso trajeto.

\section{Referências:}

BEAUCHAMP, Hélène; LARRUE, Jean-Marc. Les cycles Repère: entrevue avec Jacques Lessard, directeur artistique du Théâtre Repère. In: L'Annuaire théâtral: revue québécoise d'études théâtrales, Numéro 8, automne, p. 131-143, 1990.

BERSELLI, Marcia. Processo de criação do ator: a busca pela organicidade a partir do contato. 2014. 207 f. Dissertação (Mestrado em Artes Cênicas) - Instituto de Artes, Universidade Federal do Rio Grande do Sul, Porto Alegre, 2014.

BERSELLI, Marcia; SOLDERA, Natália. Funções flutuantes e o artista multidisciplinar. Paper apresentado em: Ciência, desenvolvimento, sociedade. $X$ Salão de Ensino UFRGS; 20 a 24 de outubro de 2014, Porto Alegre.

BOGART, Anne. A preparação do diretor: sete ensaios sobre arte e teatro. São Paulo: Editora WMF Martins Fontes, 2011.

BRESSAN, Vanessa Corso; BERSELLI, Marcia. Processos formativos em teatro: estratégias de criação mobilizando o trânsito da atenção no processo criativo. Revista da FUNDARTE, Montenegro, p.46-62, ano 19, no 38, abril/junho de 2019.

Disponível em: http://.seer.fundarte.rs.gov.br/index.php/RevistadaFundarte/index> 28 de junho de 2019. 


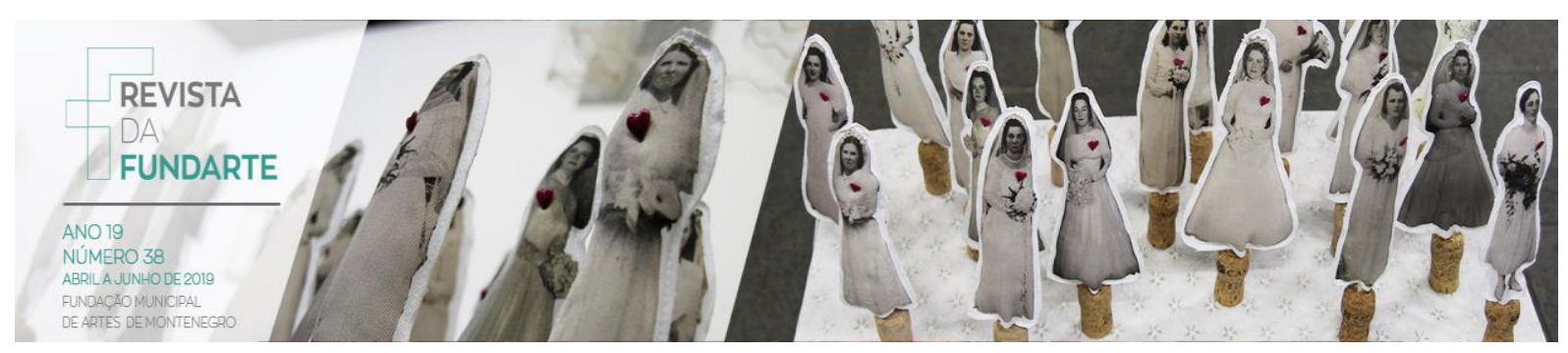

DUBATTI, Jorge. Cartografía Teatral: introducción al Teatro Comparado. Buenos Aires: Atuel, 2008.

FÉRAL, Josette. Acerca de la teatralidad. Buenos Aires: Nueva Generación, 2003.

GROTOWSKI, Jerzy. [Maio, 1969]. A voz. In: FLASZEN, L e POLLASTRELLI, C. O Teatro Laboratório de Jerzy Grotowski 1959-1969: Textos e materiais de Jerzy Grotowski e Ludwik Flaszen com um escrito de Eugenio Barba. 2ª ed. São Paulo: Perspectiva: Edições SESC SP; Pontedera, IT: Fondazione Pontedera Teatro, p. 137-162, 2010.

LEHMANN, Hans-Thies. Teatro Pós-Dramático e Teatro Político. Revista Sala Preta. São Paulo, v. 3. p. 09-19, 2003.

NELSON, Lisa. Before your Eyes: seeds of a dance practice. Contact Quarterly Dance Journal, New York, v. 29, n. 1, p. 01-05, Winter/Spring, 2003.

NETO, Francisco de Assis Gaspar. Atenciografia do Corpo: interseções entre Lisa Nelson e Gilbert Simondon a partir de um fragmento de relato. Revista Brasileira de Estudos da Presença. Porto Alegre, v. 7, n. 1, p. 205-221, jan./abr, 2017.

SILVA, Hugo Leonardo da. Desabituação compartilhada: Contato Improvisação, jogo de dança e vertigem. Valença: Selo A Editora, 2014.

STANISLAVSKI, Constantin. A preparação do ator. [Tradução de Pontes de Paula Lima]. 16ㄹ. ed. Rio de Janeiro: Civilização Brasileira, 2000.

BRESSAN, Vanessa Corso; BERSELLI, Marcia. Processos formativos em teatro: estratégias de criação mobilizando o trânsito da atenção no processo criativo. Revista da FUNDARTE, Montenegro, p.46-62, ano 19, no 38, abril/junho de 2019.

Disponível em: http://.seer.fundarte.rs.gov.br/index.php/RevistadaFundarte/index> 28 de junho de 2019. 